\title{
Plasmid transformation of Streptomyces venezuelae: modified procedures used to introduce the gene(s) for $p$-aminobenzoate synthase
}

\author{
David A. Aidoo, Katherine Barrett and Leo C. Vining \\ Biology Department, Dalhousie University, Halifax, Nova Scotia, Canada B3H $4 J 1$
}

(Received 24 May 1989; revised 22 December 1989; accepted 8 January 1990)

\begin{abstract}
Sucrose was unsuitable as an osmotic stabilizer in buffer solutions and media used for transformation of Streptomyces venezuelae ISP5230. Its replacement with $\mathrm{NaCl}$, together with other modifications in the procedure, allowed efficient formation and regeneration of protoplasts but did not support transformation of $S$. venezuelae ISP5230 by vectors pIJ41 and pIJ941. With pIJ702, transformants with a low plasmid-copy-number and altered growth characteristics were obtained. Both pIJ702 and pIJ941, but not pIJ41, transformed $S$. venezuelae 13s; when pIJ941 was used, the plasmid in 18 of 20 transformants contained a deletion in the region reported to code for replication and transfer. The modified plasmid transformed $S$. venezuelae ISP5230 efficiently and was used to introduce a fragment of DNA from the pab locus of the wild-type into a Cml-1 mutant of ISP5230 blocked in chloramphenicol formation. Transformants that overproduced $p$-aminobenzoic acid were obtained but they remained blocked in chloramphenicol production; thus, the cloned pab fragment did not contain genes able to complement the $\mathrm{cml}-1$ mutation. The results also suggest that the $\mathrm{Cml}-1$ phenotype is not due to a defective reaction common to the biosynthesis of $p$-aminobenzoic acid and chloramphenicol.
\end{abstract}

\section{Introduction}

Streptomycetes are Gram-positive filamentous bacteria that produce a diverse array of secondary metabolites, many of which have found application as antibiotics. Development of economic methods for producing these compounds has exploited the ease with which antibiotic activity can be quantitatively assessed. Rapid assay procedures have been used to screen empirically for strains with higher productivity and other desirable characteristics, usually after genetic change introduced by mutagenic treatment. However, the development of host-vector systems for gene cloning in these organisms (Bibb et al., 1980, 1983; Hunter, 1985; Hopwood et al., 1985) has introduced new opportunities for manipulating the secondary metabolic pathways and regulatory mechanisms responsible for antibiotic production.

Chloramphenicol is produced by Streptomyces venezuelae and several related species. The pathway by which the antibiotic is synthesized branches from that used for biosynthesis of protein aromatic amino acids at chorismic acid (Fig. 1), and much is now known about the biochemical reactions leading to chloramphenicol (Vining \& Westlake, 1984). The organization of the $\mathrm{cml}$ genes that specify these reactions has also been investigated (Doull et al., 1986; Vats et al., 1987). Analysis of recombinants obtained by conjugation and transduction has established that the $\mathrm{cml}$ genes are clustered on the chromosome of S. venezuelae ISP5230, and has indicated their probable arrangement.

These studies have made available a number of mutants blocked in formation of chloramphenicol. Transformation of such strains with plasmid vectors carrying wild-type genomic DNA, followed by selection of transformants complemented either for antibiotic production or for an auxotrophic requirement that maps near the $\mathrm{cml}$ genes, presents an attractive strategy for cloning the complete set of genes involved in chloramphenicol biosynthesis. This paper reports the development of procedures for efficient preparation and regeneration of $S$. venezuelae ISP5230 protoplasts, and for their transformation. It describes the use of these procedures to introduce a DNA fragment conferring the ability to overproduce $p$-aminobenzoic acid into an $S$. venezuelae strain blocked at an early step in chloramphenicol production.

\section{Methods}

Cultures. Streptomyces venezuelae strain ISP5230 (also listed as ATCC 10712) is the type strain for the species and was provided by $\mathrm{C}$. Stuttard (Stuttard, 1982). Streptomyces venezuelae strain 13s is a natural 
<smiles>C=C(OC1C=C(C(=O)O)C=CC1O)C(=O)O</smiles>

Chorismic acid

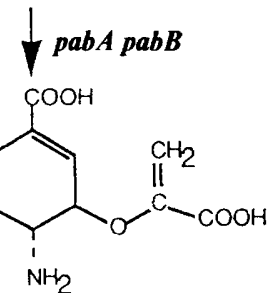

Aminochorismic acid

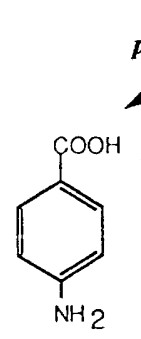

p-Aminobenzoic acid

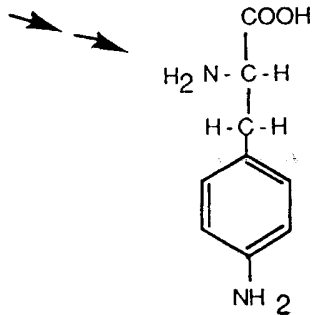

$\mathrm{NH} 2$

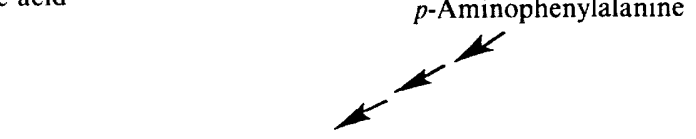<smiles>O=C(Cl)C(CO)C(O)c1ccc([N+](=O)[O-])cc1</smiles>

Chloramphenicol

Fig. 1. Conversion of chorismic acid to 4-amino-4-deoxychorismic acid and the branching reactions leading to $p$-aminobenzoic acid or, via $p$-aminophenylalanine, to chloramphenicol. The $p a b A$ and $p a b B$ genes encode $p$-aminobenzoate synthase enzymes II and I, respectively; $p a b X$ is used to designate enzyme X (Nichols et al., 1989).

variant of Streptomyces sp. 3022a selected for high chloramphenicol production (Malik \& Vining, 1970); it has been identified as $S$. venezuelae (see Ahmed \& Vining, 1983). The derivation of $S$. venezuelae strain Cml-1 has been described (Doull et al., 1985), as have methods for culturing the above strains (Malik \& Vining, 1970; Doull et al., 1986). Streptomyces lividans strains 66 and JG $10\left(p^{-} b^{-}\right)$were provided by Drs D. A. Hopwood, John Innes Institute, Norwich, UK, and J. A. Gil, Oviedo University, Spain, respectively. The plasmid vectors used were: $\mathrm{pJ} 702$, a high-copy-number vector derived from the $S$. lividans ISP5434 plasmid pIJ101 (Katz et al., 1983); pIJ41, a low-copy-number vector derived from the SLP1.2 replicon that originates in Streptomyces coelicolor A3(2) (Thompson et al., 1982a); and pIJ941, a low-copynumber vector derived from the $S$. coelicolor A3(2) plasmid SCP2* (Lydiate et al., 1985). The vectors were also gifts from Dr Hopwood.

Media. For $S$. lividans, YEME and R2YE media were used as described by Hopwood et al. (1985) except that the concentration of sucrose in YEME medium was reduced to $10.3 \%(\mathrm{w} / \mathrm{v})$ to promote sedimentation of the mycelium when cells were harvested by centrifugation. Clumping of the mycelium in cultures at the lower sucrose concentration was overcome by inoculating with spores. from confluent growth on a Petri dish. Cultures of $S$. venezuelae were grown on MYM agar (Stuttard, 1982), or in YEME medium supplemented with $1.0 \%(\mathrm{w} / \mathrm{v})$ glycine (YEME/glycine medium). Protoplasts of $S$. venezuelae were regenerated on $\mathrm{R} 5 \mathrm{~N}$ agar. This was a modification of R2 agar (Okanishi et al., 1974) in which the yeast extract content was increased to $0.5 \%$ (Thompson et al., 1980), glucose was replaced by maltose, and $0.3 \mathrm{M}-\mathrm{NaCl}$ was substituted for sucrose. Thiostrepton (20 $\mu \mathrm{g} \mathrm{m}^{-1}$ ) was added to media when necessary.

Chemicals and biochemicals. Thiostrepton was generously provided by S. J. Lucania, E. R. Squibb \& Sons, Princeton, NJ, USA. Restriction enzymes were purchased from BRL. Polyethylene glycol (PEG) 1000 was from Koch-Light. Bactopeptone, malt extract, Casamino acids and yeast extract were from Difco.

Plasmid isolation. Except where noted, plasmid DNA was isolated by the alkaline lysis procedure described by Kieser (1984) and purified by centrifugation in a $\mathrm{CsCl}$ gradient containing ethidium bromide (Maniatis et al., 1982). In some experiments, transformants were screened for the presence of plasmids by removing mycelium from cultures growing on an agar surface and suspending the cells in $0.5 \mathrm{ml}$ of the lysozyme solution before alkaline lysis.

Transformation. The general procedures used to prepare, regenerate and transform protoplasts were those described by Hopwood et al. (1985). These procedures were followed without modification for $S$. lividans. Efficiency of protoplast formation was estimated by plating samples on regeneration medium before and after treatment with $0.01 \%$ SDS in P buffer (Hopwood et al., 1985). The number of c.f.u. $\mathrm{ml}^{-1}$ obtained from the detergent-treated sample was subtracted from that given by the untreated sample and the difference was expressed as a percentage of the latter. In experiments with $S$. venezuelae ISP5230, the sucrose included in P-buffer for osmotic protection was replaced with $0.3 \mathrm{M}-\mathrm{NaCl}$. Protoplasts of $S$. venezuelae were prepared from the mycelium of cultures grown for $24 \mathrm{~h}$ in YEME/glycine medium by digesting the cell walls with lysozyme $\left(2 \mathrm{mg} \mathrm{ml}^{-1}\right)$ for $1 \mathrm{~h}$. For transformation of $S$. venezuelae, protoplasts $\left(4 \times 10^{9}\right)$ prepared in modified $\mathrm{L}$ buffer and transferred to modified $\mathrm{P}$ buffer were collected by centrifugation. The pellet was mixed with plasmid DNA $(1-2 \mu \mathrm{g})$ in not more than $20 \mu \mathrm{l}$ of TE buffer (1.0 mM-EDTA, $10 \mathrm{mM}$-Tris $/ \mathrm{HCl}, \mathrm{pH}$ 8.0 ), then immediately diluted with $0.5 \mathrm{ml}$ of modified $\mathrm{T}$ buffer containing $25 \%$ PEG 1000 . After $3 \mathrm{~min}, 5 \mathrm{ml}$ of modified $\mathrm{P}$ buffer was added; the transformed protoplasts were collected by centrifugation, resuspended in modified $\mathrm{P}$ buffer and regenerated on R5N agar. The compositions of $\mathrm{L}, \mathrm{P}$, and $\mathrm{T}$ buffers (Thompson et al., 1982b; Hopwood et al., 1985) were modified by replacing sucrose with $0.3 \mathrm{M}-\mathrm{NaCl}$.

Conjugative plasmids. As an indication of the ability of plasmids to promote conjugation in $S$. lividans, cultures were tested for pock formation as described by Hopwood et al. (1985).

Analyses. Assays for antibiotic activity were done as described by Doull et al. (1985). Total aromatic amino and nitro compounds in culture broths were determined colorimetrically by the procedure (Levine \& Fischbach, 1951) used to measure chloramphenicol. Samples for thin-layer chromatography (TLC) were extracted from filtered broth at neutral $\mathrm{pH}$ with ethyl acetate and were applied to silica gel (Sil $60 \mathrm{~F}_{254}$ ). Chromatograms were developed with benzene/acetic acid/ water ( $42: 24: 1$, by vol.), examined under light of $254 \mathrm{~nm}$ and sprayed with dimethylaminobenzaldehyde. The $R_{F}$ values of $p$-aminobenzoic acid and chloramphenicol in this system were 0.50 and 0.27 , respectively. 


\section{Results}

\section{Sucrose-stabilized media}

Attempts to form protoplasts from the mycelium of $S$. venezuelae ISP5230 grown in YEME/glycine medium and digested at $30^{\circ} \mathrm{C}$ for $1-3 \mathrm{~h}$ with lysozyme in $\mathrm{L}$ buffer, as described by Hopwood et al. (1985) for $S$. lividans, consistently gave yields below $70 \%$. Under these conditions, $S$. lividans mycelium gave the expected high yield of protoplasts, and then could be transformed to thiostrepton resistance by pIJ702, pIJ41 and pIJ941 isolated from $S$. lividans with efficiencies of $10^{6}-10^{7}(\mu \mathrm{g}$ DNA) $)^{-1}$. In contrast, transformation of the protoplasts prepared from $S$. venezuelae with these same vectors gave, under comparable conditions, no thiostreptonresistant colonies.

\section{Replacement of sucrose}

Mycelium of $S$. venezuelae readily formed protoplasts when incubated with lysozyme in the TE buffer used for genomic DNA isolation. This buffer lacks sucrose, and addition of $0.3 \mathrm{M}$-sucrose to it caused a severe reduction in protoplast formation. Omission of sucrose from the $\mathrm{L}$ buffer normally used for preparing protoplasts gave improved yields, but the osmotic fragility of protoplasts prepared in such unsupplemented buffers prevented their successful transformation. Substitution of $20 \%$ $(\mathrm{w} / \mathrm{v})$ glycerol or $0.3 \mathrm{M}-\mathrm{NaCl}$ for the sucrose in $\mathrm{L}$ buffer stabilized the protoplasts without reducing the $95-99 \%$ yield from digestion of the cell walls with lysozyme. Media stabilized osmotically with glycerol did not support regeneration, but on R2YE or R5N agar, $90 \%$ of the protoplasts regenerated.

Protoplasts of $S$. venezuelae ISP5230 prepared by the modified procedure could not be transformed by pIJ702, pIJ41 or pIJ941 when they were regenerated on R2YE agar. However, transformation with pIJ702 succeeded when protoplasts prepared in $\mathrm{NaCl}$-stabilized modified $\mathrm{L}$ buffer were regenerated on $\mathrm{R} 5 \mathrm{~N}$ agar, in which sucrose is replaced with $\mathrm{NaCl}$. Similar attempts with pIJ41 or pIJ941 were not successful. Protoplasts transformed with pIJ702 isolated from S. lividans gave 100 thiostreptonresistant colonies ( $\mu \mathrm{g} \mathrm{DNA})^{-1}$, but growth of the colonies was slow, both on R5N agar and after subsequent transfer to MYM agar. The plasmid isolated from transformants was indistinguishable from pIJ702 in its mobility during agarose gel electrophoresis and fragmentation pattern with restriction enzymes, but absorbance measurements at $260 \mathrm{~nm}$ showed that its concentration was only about $1 \%$ of that in $S$. lividans transformants. Transformation of $S$. venezuelae with plasmid DNA isolated from the primary transformants gave $10^{3}$ thiostrepton-resistant colonies ( $\mu$ g DNA $)^{-1}$. These transformants exhibited the same slow-growth characteristics and low plasmid content as those from the initial transformation. When $S$. lividans JG10 was transformed under the conditions described by Hopwood et al. (1985) with pIJ702 isolated from the $S$. venezuelae transformants, $10^{6}-10^{7}$ thiostrepton-resistant colonies ( $\mu$ g DNA $)^{-1}$ were obtained. These grew at the normal rate, and the plasmid isolated from them could not be distinguished by restriction endonuclease analysis from the original pIJ702.

\section{Modified vector}

To determine whether another strain of $S$. venezuelae might be more amenable than ISP 5230 to transformation with $\mathrm{pIJ} 702, S$. venezuelae $13 \mathrm{~s}$ protoplasts were transformed with vector DNA isolated from S. lividans 66 . Regardless of whether the transformation conditions used were those developed for $S$. lividans or for $S$. venezuelae ISP5230, thiostrepton-resistant colonies were obtained at frequencies of $10^{6}(\mu \mathrm{g} \text { DNA })^{-1}$. Similar results were obtained with pIJ941, whereas no transformants were obtained with pIJ41. Transformation of ISP5230, under conditions optimized for this strain, with pIJ702 DNA recovered from 13s transformants gave approximately 100 slow growing colonies ( $\mu$ g DNA) ${ }^{-1}$, as found with pIJ702 DNA isolated directly from $S$. lividans 66.

Thiostrepton-resistant colonies from $S$. venezuelae $13 \mathrm{~s}$ protoplasts transformed with pIJ941 contained one of two types of plasmid. Gel electrophoresis of plasmid DNA extracted from 20 of the colonies showed only two samples that corresponded in mobility with pIJ941; the remaining 18 colonies contained a smaller plasmid, designated $\mathrm{pDQ} 101$. Whereas efforts to transform strain ISP5230 with pIJ941 isolated from the appropriate $S$. venezuelae $13 \mathrm{~s}$ transformants failed, comparable experiments with pDQ101 yielded thiostrepton-resistant colonies at a frequency of $2 \times 10^{2}(\mu \mathrm{g} \text { DNA })^{-1}$. The frequency increased to $10^{5}(\mu \mathrm{g} \text { DNA })^{-1}$ when ISP5230 was subsequently transformed with $\mathrm{pDQ} 101$ isolated from ISP5230. Both pIJ941 isolated from strain 13s and pDQ101 isolated from strain ISP5230 transformed $S$. lividans JG10 efficiently, yielding thiostrepton-resistant colonies at frequencies of $10^{6}$ transformants $(\mu \mathrm{g}$ DNA $)^{-1}$.

\section{Characterization of $p D Q 101$}

Restriction enzyme analysis of pIJ941 and pDQ101 showed that in pDQ101 a $5 \cdot 3 \mathrm{~kb}$ fragment had been deleted from the $25.0 \mathrm{~kb}$ parent plasmid (Fig. 2). The deletion was 


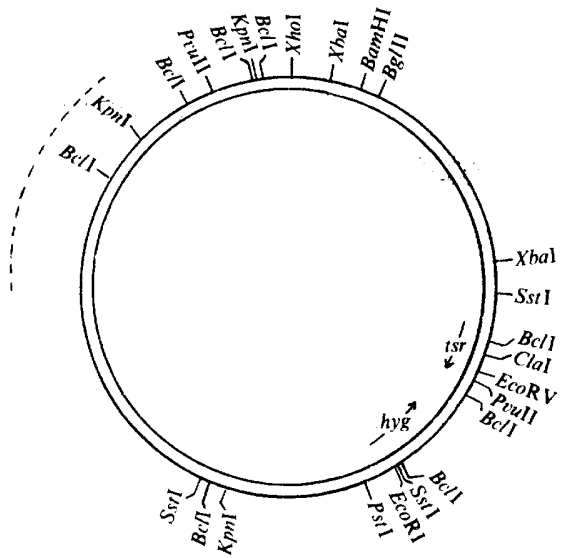

Fig. 2. Recognition sites for restriction enzymes on pIJ941 (redrawn from Lydiate et al., 1985). The approximate location of the $5.3 \mathrm{~kb}$ deletion that gives pDQ101 is indicated by the dashed line.

located at the 10 o'clock position on the pIJ941 map (Lydiate et al., 1985) and encompassed the KpnI and BclI sites in this region. Since the region codes for plasmid replication and transfer functions (Hopwood et al., 1985; Larson \& Hershberger, 1986), the ability of pDQ101 to form pocks after transfer by conjugation was tested. In contrast to a strain of S. lividans JG10 containing pIJ941, transformants containing $\mathrm{pDQ} 101$ did not generate pocks when they were plated on a lawn of the parent.

\section{Use of $p D Q 101$ to introduce a pab gene into $S$. venezuelae Cml-1}

The initial reaction in the formation of $p$-aminobenzoic acid and $p$-aminophenylalanine (Fig. 1) is the conversion of chorismic acid to 4-amino-4-deoxychorismic acid (Teng et al., 1985). Doull et al. (1985) isolated a mutant of ISP5230 blocked in chloramphenicol biosynthesis at a step between chorismic acid and $p$-aminophenylalanine. This Cml-1 mutant is not auxotrophic for $p$-aminobenzoic acid so, unless the genes for $p$-aminobenzoate synthase are present in $S$. venezuelae ISP5230 as separate alleles for primary and secondary metabolic pathways, the $\mathrm{Cml}^{-}$mutation affects a step after the pathways diverge. Since the genes for chloramphenicol biosynthesis are clustered (Vats et al., 1987), a sufficiently large DNA fragment carrying the $p a b$ gene might also contain cml-1. By complementing the defective gene, such a fragment should restore chloramphenicol synthesis when introduced into the mutant. The vector pDQ101 was used to carry out the transformation.

A $5.75 \mathrm{~kb}$ S. venezuelae ISP5230 DNA fragment complementing the defective $p a b$ gene in S. lividans JG10 (Gil \& Hopwood, 1983) was available as an insert in pIJ41 (D. A. Aidoo, unpublished). From the recombinant vector, a PstI fragment that included the insert and

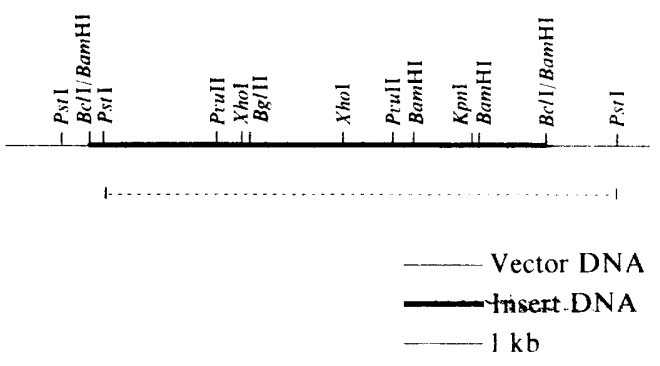

Fig. 3. Restriction map of the $S$. venezuelae ISP5230 DNA insert and adjacent DNA in pIJ41 that complements the pab mutation in $S$. lividans JG10. The dashed line below shows the PstI fragment subcloned in pDQ102 and pDQ103.

approximately $0.8 \mathrm{~kb}$ of adjacent vector DNA (Fig. 3) was ligated to Pst $\mathrm{I}$-digested $\mathrm{pDQ} 101$. The ligation mixture was used to transform $S$. venezuelae strain $13 \mathrm{~s}$ and thiostrepton-resistant colonies $\left[10^{5}(\mu \mathrm{g} \text { DNA })^{-1}\right]$ were isolated. Six of 50 transformants, screened by gel electrophoresis of extracted plasmid DNA, contained pDQ101 with the PstI fragment insert. Restriction enzyme analysis of the recombinant plasmids from these strains showed the insert to be present in both orientations. Plasmids pDQ102 and pDQ103, recombinants with oppositely oriented PstI inserts, both complemented the defective $p a b$ gene when introduced into $S$. lividans JG10 by transformation.

Plasmid pDQ102 was used to transform $S$. venezuelae Cml-1. Putative transformants were selected on R5N regeneration medium containing thiostrepton and then screened for the presence of pDQ102. Only two out of 12 colonies examined contained the recombinant plasmid. One of the two (VS607) and one of the plasmidless colonies (VS612) were compared with the host strain for production of aromatic amines and nitro compounds during growth of cultures in a medium that supported chloramphenicol production (Doull et al., 1985). The yields of mixed product were 63,30 and $3 \mu \mathrm{g} \mathrm{ml}^{-1}$, respectively. By TLC of extracts from the filtered broth, $p$-aminobenzoic acid was identified as a major product of strains VS607 and VS612, whereas it was absent from cultures of $S$. venezuelae $\mathrm{Cml}-1$.

When thiostrepton-resistant colonies obtained after transformation of the Cml-1 mutant with $\mathrm{pDQ} 102$ were assayed for production of inhibitory substances by overlaying the surrounding agar surface with Micrococcus luteus, some (including VS607 and VS612) gave small $(5-8 \mathrm{~mm})$ zones of inhibition around their margins. In parallel experiments, colonies of $S$. venezuelae $\mathrm{Cml}-1$ transformed with $\mathrm{pDQ} 101$ showed no inhibition zones and those of the wild-type chloramphenicol producer, $S$. venezuelae ISP5230, gave $18 \mathrm{~mm}$ inhibition zones. However, cultures of strains VS607 and VS612 grown in chloramphenicol production medium did not yield any 
compound with the solvent extractability and chromatographic properties of chloramphenicol.

\section{Discussion}

Streptomyces phaeochromogenes strain NRRL B3559, which produces chloramphenicol, contains a resident plasmid, pJV1 (Doull et al., 1983), which has been developed into the cloning vector pWOR109 (Bailey et al., 1986). In preliminary experiments, $\mathrm{pJV} 1$ modified by the insertion of antibiotic-resistance genes failed to transform $S$. venezuelae ISP5230. Similar results were obtained with a vector developed from the plasmid pUC3 which Malik \& Reusser (1979) isolated from the chloramphenicol-producing $S$. venezuelae strain $13 \mathrm{~s}$. No successful attempts to transform chloramphenicol-producing strains have yet been reported.

Sucrose has been used as the osmotic stabilizer in most buffers devised for the preparation and regeneration of streptomycete protoplasts. Use of $\mathrm{NaCl}$ in regeneration media was reported (Shirahama et al., 1981) to be ineffective, although its addition to $\mathrm{P}$ buffer for preparing protoplasts of the cephamycin producer Streptomyces wadayamensis has since been shown to be beneficial (Acebal et al., 1986). With $S$. venezuelae ISP5230, use of sucrose severely reduced the yield of protoplasts. Although the conditions used to grow mycelium influenced the efficiency of protoplast formation, it was only after sucrose had been replaced with $\mathrm{NaCl}$ that reproducible high yields of protoplasts were obtained. Furthermore, the protoplasts, in contrast to those obtained with sucrose-containing buffers, regenerated well and could be transformed with cloning vectors derived from $S$. coelicolor and $S$. lividans plasmids. By substituting maltose for glucose in $\mathrm{NaCl}$-containing protoplast regeneration medium, the regeneration frequency was increased by $10 \%$, a result similar to that reported by Acebal et al. (1986).

Restriction-modification systems are common in streptomycetes (Lomovskaya et al., 1977; Chater \& Carter, 1978; Stuttard, 1979) but can be bypassed by obtaining the cloning vector from transformants that escaped the restriction barrier in the primary transformation (Hunter \& Friend, 1984; Engel, 1987; Matsushima et al., 1987). It is likely that restriction activity is present in S. venezuelae ISP5230, since higher transformation efficiencies were obtained when vector plasmids were reisolated from the homologous strain. Thus the number of thiostrepton-resistant colonies obtained was greater by 10 and 1000 times, respectively, when ISP 5230 was transformed with pIJ702 and pDQ101 isolated from ISP5230 than when the plasmids were isolated from $S$. lividans. However, this was not the principal source of the difficulty encountered in developing a transformation system for $S$. venezuelae ISP5230.

The event that contributed most to obtaining an efficient host-vector system proved to be the recovery of a deletion mutant of pIJ941 following transformation of S. venezuelae 13s. Unlike pIJ941, the derivative $\mathrm{pDQ} 101$ plasmid was stably maintained in strain ISP5230. The deletion that generated pDQ101 from pIJ941, so allowing efficient transformation of ISP5230, removed DNA from the region associated with replication of the parent SCP2* plasmid in $S$. coelicolor (Lydiate et al., 1985). Within the replication region, three of four segments defined by subcloning experiments and identified as pdlA, pdlB and $p d l C$, influence plasmid copynumber (Larson \& Hershberger, 1986). The fourth segment is essential for replication and is clearly retained in $\mathrm{pDQ} 101$ since the plasmid is maintained in S. lividans. The deletion in pDQ101 extends over $p d l A$ and into the adjacent tra region involved in plasmid self-transmission. Most likely it is the removal of the negatively acting copy control element $p d l A$ from pIJ941 that allows the modified plasmid pDQ101 to be maintained in $S$. venezuelae strains $13 \mathrm{~s}$ and ISP5230.

The apparent reduction in copy number of pIJ702 when it is transferred to ISP5230 may be due to a similar control element that is more strongly expressed in the $S$. venezuelae strain than in $S$. lividans. The situation is analogous to that found with incompatible plasmids and suggests that a resident plasmid in strain ISP5230 might participate in the suppression of pIJ941. A search for extrachromosomal covalently closed circular DNA in ISP5230 failed to detect plasmids (Ahmed \& Vining, 1983), despite evidence for the involvement of extrachromosomal elements in conjugative recombination (Doull et al., 1986). However, a large linear plasmid has subsequently been discovered in this strain of $S$. venezuelae (Kinashi \& Shimaji, 1987).

When pDQ102 was used to introduce a homologous gene for $p$-aminobenzoate synthase into a $\mathrm{Cml}^{-}$mutant of $S$. venezuelae ISP5230, recombinant plasmids were detected in only a small fraction of thiostrepton-resistant transformants. The absence of an autonomous plasmid in most of the transformants can be accounted for by its integration into the bacterial chromosome, possibly as a result of recombination at the homologous pab regions. Evidence supporting this conclusion has been obtained by using the thiostrepton-resistance gene excised from pIJ702 as a hybridization probe; although transformant VS612 contained no detectable plasmid, a region in its genomic DNA hybridized with the thiostrepton resistance gene (D. A. Aidoo, unpublished).

The hope that transformants of $S$. venezuelae $\mathrm{Cml}-1$ into which a DNA fragment carrying pab genes from the wild-type were introduced might be restored for anti- 
biotic production was not realized. Although these strains overproduced $p$-aminobenzoic acid to the extent that it accumulated in the culture broth, indicating that they may have acquired multiple copies of DNA promoting $p$-aminobenzoate synthesis, they did not acquire the ability to produce chloramphenicol. Since the common biosynthetic intermediate for both $p$-aminobenzoate and chloramphenicol must have been produced in substantial quantity, the mutant gene responsible for the inability to make $p$-aminophenylalanine in strain $\mathrm{Cml}-1$ is not a defective secondary metabolic allele of pabA or $p a b B$. Failure to restore chloramphenicol production presumably means also that the DNA introduced in pDQ102 does not contain a wild-type allele of the mutation in strain $\mathrm{Cml}-1$.

This work was supported by the Natural Sciences and Engineering Research Council of Canada. We thank C. Stuttard, D. A. Hopwood and J. A. Gil for gifts of plasmids and cultures, and S. J. Lucania for providing thiostrepton. We also thank Dr Stuttard for many helpful discussions.

\section{References}

ACEbal, C., Rubio, V. \& MARQuez, G. (1986). A method to transform the $\beta$-lactam antibiotic producer, Streptomyces wadayamensis. FEMS Microbiology Letters 35, 79-82.

AHMED, Z. U. \& VINING, L. C. (1983). Evidence for a chromosomal location of the genes coding for chloramphenicol production in Streptomyces venezuelae. Journal of Bacteriology 154, 239-244.

Bailey, C. R., Bruton, C. J., Butler, M. J., Chater, K. F., Harris, J. E. \& HOPWOOD, D. A. (1986). Properties of in vitro recombinant derivatives of pJV1, a multi-copy plasmid from Streptomyces phaeochromogenes. Journal of General Microbiology 132, 2071-2078.

BiBb, M. J., SCHotTel, J. L. \& CoheN, S. N. (1980). A DNA cloning system for interspecies gene transfer in antibiotic-producing Streptomyces. Nature, London 274, 398-400.

BibB, M. J., Chater, K. F. \& Hopwood, D. A. (1983). Developments in Streptomyces cloning. In Experimental Manipulation of Gene Expression, pp. 53-82. Edited by M. Inouye. New York: Academic Press.

CHATER, K. F. \& CARTER, A. T. (1978). Restriction of a bacteriophage in Streptomyces albus P (CMI 52766) by endonuclease SalP1. Journal of General Microbiology 109, 181-185.

Doull, J. L., Vining, L. C. \& StuttaRd, C. (1983). A cryptic plasmid in the chloramphenicol-producing actinomycete, Streptomyces phaeochromogenes. FEMS Microbiology Letters 16, 349-352.

Doull, J., AHMED, Z., StutTARD, C. \& VINING, L. C. (1985). Isolation and characterization of Streptomyces venezuelae mutants blocked in chloramphenicol biosynthesis. Journal of General Microbiology 131, 97-104.

Doull, J. L., Vats, S., Chaliciopoulos, M., Stuttard, C., Wong, K. \& VINING, L. C. (1986). Conjugational fertility and location of chloramphenicol biosynthetic genes on the chromosome linkage map of Streptomyces venezuelae. Journal of General Microbiology 132, $1327-1338$.

ENGEL, P. (1987). Plasmid transformation of Streptomyces tendae after heat attenuation of restriction. Applied and Environmental Microbiology 53, 1-3.

GIL, J. A. \& HopwOOD, D. A. (1983). Cloning and expression of a paminobenzoic acid synthetase gene of the candicidin-producing Streptomyces griseus. Gene 25, 119-132.

Hopwood, D. A., Bibb, M. J., Chater, K. F., Kieser, T., Bruton, C., Kieser, H. M., Lydiate, D. J., Smith, C. P., Ward, J. M. \& SCHREMPF, H. (1985). Genetic Manipulation of Streptomyces. A Laboratory Manual. Norwich, UK: John Innes Foundation.
HUNTER, I. S. (1985). Gene cloning in Streptomyces. In DNA cloning, Vol. 2, pp. 19-44. Edited by D. M. Glover. Oxford: IRL Press.

HUNTER, I. S. \& FRIEND, E. J. (1984). "Restriction-deficient" mutants of industrial Streptomyces. Biochemical Society Transactions 12, 643644.

Katz, E., Thompson, C. J. \& Hopwood, D. A. (1983). Cloning and expression of the tyrosinase gene from Streptomyces antibioticus in Streptomyces lividans. Journal of General Microbiology 129, 27032714.

KIESER, T. (1984). Factors affecting the isolation of ccc DNA from Streptomyces lividans and Escherichia coli. Plasmid 12, 19-36.

KINASHI, H. \& SHIMAJI, M. (1987). Detection of giant linear plasmids in antibiotic-producing strains of Streptomyces by the OFAGE technique. Journal of Antibiotics 40, 913-916.

LARSON, J. L. \& HERSHBERGER, C. L. (1986). The minimum replicon of a streptomycete plasmid produces an ultra-high level of plasmid DNA. Plasmid 15, 199-209.

LEVINE, J. \& FisChBACH, H. (1951). The chemical determination of chloramphenicol in biological materials. Antibiotics and Chemotherapy 1, 59-62.

Lomovskaya, N. D., Voeykova, T. A. \& Mkrtumian, N. M. (1977). Construction and properties of hybrids obtained in interspecific crosses between Streptomyces coelicolor A3(2) and Streptomyces griseus Kr. 15. Journal of General Microbiology 98, 187-198.

Lydiate, D. J., Malpartida, F. \& Hopwood, D. A. (1985). The Streptomyces plasmid SCP2*: its functional analysis and development into useful cloning vectors. Gene 35, 223-235.

Malik, V. S. \& Reusser, F. (1979). Restriction enzyme map for streptomycete plasmid pUC3. Plasmid 2, 627-631.

MALIK, V. S. \& VINING, L. C. (1970). Metabolism of chloramphenicol by the producing organism. Canadian Journal of Microbiology 16, 173-180.

Maniatis, T., Fritsch, E. F. \& Sambrook, J. (1982). Molecular Cloning: a Laboratory Manual. Cold Spring Harbor, NY: Cold Spring Harbor Laboratory.

Matsushima, P., Cox, K. L. \& Baltz, R. H. (1987). Highly transformable mutants of Streptomyces fradiae defective in several restriction systems. Molecular and General Genetics 206, 393-400.

Nichols, B. P., Seibold, A. M. \& DokToR, S. Z. (1989). pAminobenzoate synthesis from chorismate occurs in two steps. Journal of Biological Chemistry 264, 8597-8601.

OKanishi, M., Suzuki, K. \& UmezaWa, H. (1974). Formation and reversion of streptomycete protoplasts: cultural conditions and morphological study. Journal of General Microbiology 80, 389-400.

Shirahama, T., Furumai, T. \& OKanishi, M. (1981). A modified regeneration method for streptomycete protoplasts. Agricultural and Biological Chemistry 45, 1271-1273.

StUTTARD, C. (1979). Transduction of auxotrophic markers in a chloramphenicol-producing strain of Streptomyces. Journal of General Microbiology 110, 479-482.

STUTTARD, C. (1982). Temperate phages of Streptomyces venezuelae: lysogeny and host specificity shown by SV1 and SV2. Journal of General Microbiology 128, 115-121.

Teng, C.-Y. P., Ganem, B., Doktor, S. Z., Nichols, B. P., BhatnagaR, R. K. \& Vining, L. C. (1985). Total synthesis of $( \pm)$ 4amino-4-deoxychorismic acid: a key intermediate in the biosynthesis of para-aminobenzoic acid and L-para-aminophenylalanine. Journal of the American Chemical Society 107, 5008-5009.

THOMPSON, C. J., WARD, J. M. \& HoPwOOD, D. A. (1980). DNA cloning in Streptomyces: resistance genes from antibiotic-producing species. Nature, London 286, 525-527.

THOMPSON, C. J., KIESER, T., W ARD, J. M. \& HopWOOD, D. A. (1982a). Physical analysis of antibiotic resistance genes from Streptomyces and their use in vector construction. Gene 20, 51-62.

Thompson, C. J., WARD, J. M. \& Hopwood, D. A. (1982b). Cloning of antibiotic resistance and nutritional genes in streptomycetes. Journal of Bacteriology 151, 668-672.

Vats, S., Stuttard, C. \& Vining, L. C. (1987). Transductional analysis and mutagenesis of chloramphenicol biosynthesis genes in Streptomyces venezuelae. Journal of Bacteriology 169, 3809-3813.

VINING, L. C. \& Westlake, D. W. S. (1984). Chloramphenicol: properties, biosynthesis and fermentation. In Biotechnology of Industrial Antibiotics, pp. 387-411. Edited by E. J. Vandamme. New York: Marcel Dekker. 